\title{
Study Investigator Role
}

National Cancer Institute

\section{Source}

National Cancer Institute. Study Investigator Role. NCI Thesaurus. Code C71099.

The responsibility of the investigator on a particular study as defined in the study protocol. 